\title{
ANALISIS KOMPETENSI DOSEN DAN ALUMNI FAKULTAS EKONOMI DAN BISNIS UNIVERSITAS MATARAM
}

\author{
Zainal Abidin ${ }^{1}$, Weni Retnowati ${ }^{2}$, AlamsyahAB $^{3}$ \\ ${ }^{1}$ Fakultas Ekonomi dan Bisnis, Universitas Mataram, zainal.abidin@unram.ac.id \\ ${ }^{2}$ Fakultas Ekonomi dan Bisnis, Universitas Mataram,weniretnowati@unram.ac.id \\ ${ }^{3}$ Fakultas Ekonomi dan Bisnis, Universitas Mataram,alamsyahab@unram.ac.id
}

\begin{abstract}
ABSTRAK
Penelitian ini bertujuan untuk mengetahui kompetensi dosen jurusan manajemen, lama masa tunggu para alumni manajemen dalam memasuki dunia kerja, kesesuaian antara latar belakang pendididikan dengan pekerjaan yang ditekuni dan tingkat kompetensi para alumni jurusan manajemen Fakultas Ekonomi dan Bisnis Universitas Mataram. Jenis penelitian ini deskriptif dengan obyek penelitian semua dosen dan alumni juruasan manajemen Fakultas Ekonomi dan Bisnis Universitas Mataram tahun lulusan 2016. Alat analisis yang digunakan dalam penelitian ini dengan reduksi data, penyajian data, diskripsi data dengan bantuan statistik deskriptif. Hasil penelitian menunjukkan $95,08 \%$ berperilaku sangat baik dan sisanya berperilaku baik, tingkat Pendidikan dosen $41,67 \%$ berpendidikan S3 dan 58,33\% berpendidikan S2. Lama masa menunggu para alumni memasuki dunia kerja $72,72 \%$ kurang dari 6 bulan, 15,15\% antara 7 sampai dengan 9 bulan dan sisanya di atas 10 bulan. Sedangkan kesesuaian antara latar belakang Pendidikan dengan pekerjaan yang ditekuni $8,16 \%$ menyatakan sangat erat, $32,65 \%$ menyatakan erat dan $8,16 \%$ menyatakan tidak ada.
\end{abstract}

Kata Kunci: Kompetensi dosen dan alumni jurusan manajemen

\begin{abstract}
This study aims to determine the competence of the management department lecturers, the length of the waiting period of alumni in entering the workforce, the suitability between the educational background and the occupation and alumni competency after finishing their study at Department of Management in Economics and Business Faculty. This type of research is descriptive with the research object are all lecturers in Management Department and alumni of the Faculty of Economics and Business, University of Mataram which were graduated in 2016. The analysis data that were used in this research are data reduction, statistic descriptive and other statistic function to gain a conclution. The research data results 95.08\% lecturer are described by students as excellent and others consider as good. As $41.67 \%$ lecturer are doctoral graduated, whilst $58.33 \%$ are master graduated. The time needed by alumni to get a job data shows that $72.72 \%$ alumni's waiting time is less than 6 months, $15.15 \%$ alumni's waiting time is 7 to 9 months and others need more than 10 months. The aligning between education background and job they take describe as: $8.16 \%$ alumni declare it is highly correlated, $32.65 \%$ said its moderate correlated, whilst $8.16 \%$ said there is no correlation between their education and their job.
\end{abstract}

Keywords: Lecturer Competency, Alumni, Department of Management 


\section{PENDAHULUAN}

Fakultas Ekonomi dan Bisnis Universitas Mataram sebagai salah satu lembaga pendidikan tinggi negeri di Nusa Tenggara Barat (NTB) tidak boleh ketinggalan dalam memajukan dunia pendidikan melalui peningkatan kinerja akademik terutama dalam menyelaraskan kurikulum yang ada dengan berbagai stakeholders sehingga dapat melahirkan lulusan yang berkualitas secara akademis dan terampil dalam menjalankan pekerjaan didunia kerja. Peningkatan jumlah lulusan perguruan tinggi dan semakin sempitnya lapangan pekerjaan maka para alumni dituntut memiliki pengetahuan, keterampilan, pengalaman serta penguasaan teknologi yang dibutuhkan dunia kerja

Tuntutan akan kompetensi para pendidik (dosen) dan lulusan merupakan faktor pendorong untuk melakukan perbaikan dan pembenahan dalam rencana strategis kedepan seperti proses pelaksanaan akademis, serta kelengkapan sarana dan prasarana yang dibutuhkan dalam dunia pendidikan. Proses pendidikan yang dilakukan diharapkan akan menghasilakan sumberdaya manusia beriman dan bertaqwa kepada Tuhan Yang Maha Esa, berbudi pekerti luhur, memiliki kopetensi dalam bidangnya, dan berwawasan global. Dari proses tersebut diharapkan juga akan dihasilkan ilmu pengetahuan dan teknologi yang dapat menambah hasanah ilmu pengetahuan, dan menjadi rujukan pemecahan masalah di masyarakat, dalam rangka mendukung proses pembelajaran bermutu kepada mahasiswa dan pengabdian kepada masyarakat, sehingga dapat berkonstribusi untuk memecahkan berbagai persoalan yang timbul di masyarakat, mendorong pertumbuhan ekonomi, dan membangun sosial serta budaya masyarakt Indonesia.

Fakultas Ekonomi dan Bisnis (FEB) Universitas Mataram memiliki Visi, yaitu "Menjadi lembaga pendidikan tinggi berbasis riset berdaya saing internasional tahun 2025". Untuk merealisasikan visi tersebut FEB menyelenggarakan misi, yaitu ; a) Melaksanakan proses pendidikan tinggi berstandar mutu nasional dan internasional yang berbasis riset yang kuat, b) melaksanakan kegiatan riset berstandar mutu nasional dan internasional, c) melaksanakan pengabdian kepada masyarakat yang didasari pada hasil riset, dalam rangka memberikan kontribusi untuk memecahkan berbagai persoalan yang timbul di masyarakat, mendorong pertumbuhan ekonomi, dan membangun sosial serta budaya masyarakt Indonesia, d) membangun jaringan kerjasama yang luas dengan berbagai pihak instansi pemerintah dan swasta, di dalam dan luar negeri, dan e) melaksanakan tata kelola aset, keuangan dan administrasi yang memenuhi standar tata kelola Universitas yang baik, efisien, efektif, transparan dan akuntable (good university governance),

Pertanyaan yang sering muncul setelah seseorang menyelesaikan jenjang pendidikan tinggi ialah akan kerja apa, di mana, dan untuk siapa. Pertanyaan tersebut mengindikasikan perubahan kesadaran sekaligus harapan bahwa pengetahuan dan keterampilan yang diperoleh di bangku kuliah dapat bermanfaat bagi orang lain melalui karya nyata sang sarjana.

Jurusan Manajemen regular pagi pada tahun 2016 melalui empat kali wisuda telah meluluskan alumni sebanyak orang, penelusuran secara menyeluruh dan berkelanjutan terhadap para pendidik dan para lulusannya perlu dilakukan. Penelusuran yang dilakukan selama ini bersifat terbatas dalam bentuk sampel yang kecil. Oleh karenanya

perlu dilakukan penelusuran secara menyeluruh tentang kompetensi dosen dan Keberadaan alumni setelah lulus.

\section{Rumusan Masalah}

Berdasarkan latar belakang di atas maka rumusan masalahnya adalah sebagai 
berikut: Bagaimana kompetensi dosen jurusan manajemen FEB Unram, berapa lama masa tunggu para alumni dalam memasuki dunia kerja?

\section{Tujuan Penelitian}

Adapun tujuan dari penelitian ini adalah untuk mengetahui kompetensi dosen jurusan Manajemen FEB Unram, lama masa tunggu para alumni dalam memasuki dunia kerja, kesesuaian antara latar belakang pendidikan dengan pekerjaan yang ditekuni.

\section{Pengertian Kompetensi}

\section{TINJAUAN LITERATUR}

Menurut Kamus Kompetensi LOMA (1998), kompetensi didefinisikan sebagai aspek-aspek pribadi dari seorang pekerja yang memungkinkan dia untuk mencapai kinerja yang superior. Aspek-aspek pribadi ini termasuk sifat, motif-motif, sistem nilai, sikap, pengetahuan, dan ketrampilan. Kompetensi-kompetensi akan mengarahkan tingkah laku. Sedangkan tingkah laku akan menghasilkan kinerja.

\section{Komptensi Dosen}

Dosen adalah sebuah profesi yang memerlukan kualifikasi dan kompetensi dosen tertentu. Seperti dengan Dokter dan profesi yang lain, kualifikasi dan kompetensi Dosen ditentukan dan diatur oleh Undang - Undang. Secara rinci diatur dalam Undang-Undang Nomor 14 tahun 2005, tentang Guru dan Dosen. Dalam UU tersebut dijelaskan bahwa Dosen wajib memiliki kualifikasi akademik, kompetensi, sertifikat pendidik, sehat jasmani dan rohani, dan memenuhi kualifikasi lain yang dipersyaratkan satuan pendidikan tinggi tempat bertugas, serta memiliki kemampuan untuk mewujudkan tujuan pendidikan.

Kualifikasi Akademik Dosen yang dimaksud adalah minimal melalui pendidikan tinggi program pascasarjana yang terakreditasi sesuai dengan bidang ilmu keahlian. Jlka dahulu lulusan sarjana bisa menjadi dosen, setelah keluarnya UU tersebut mewajibkan seorang dosen bergelar magister untuk mengajar program diploma dan sarjana. Dan lulusan program doktor utnuk mengajar program pascasarjana.

Sertifikat pendidik untuk Dosen diberikan setelah memenuhi beberapa syarat antara lain: a) memiliki pengalaman kerja sebagai pendidik pada perguruan tinggi sekurangkurangnya dua tahun, b) memiliki jabatan akademik sekurang-kurangnya asisten ahli, c) lulus sertifikasi yang dilakukan oleh perguruan tinggi yang menyelenggarakan program pengadaan tenaga kependidikan pada perguruan tinggi yang ditetapkan oleh Pemerintah.

Sertifikasi pendidik untuk dosen dilaksanakan melalui uji kompetensi dosen untuk memperoleh sertifikat pendidik. Uji kompetensi sebagaimana dimaksud dilakukan dalam bentuk penilaian portofolio.Penilaian Portofolio merupakan penilaian pengalaman akademik dan profesional dengan menggunakan portofolio dosen. Penilaian portofolio dosen dilakukan untuk menentukan pengakuan atas kemampuan profesional dosen, dalam bentuk penilaian terhadap kumpulan dokumen yang mendiskripsikan tentang: a) kualifikasi akademik dan unjuk kerja tridharma perguruan tinggi; b) persepsi dari atasan, sejawat, mahasiswa dan diri sendiri tentang kepemilikan kompetensi pedagogik, profesional, sosial dan kepribadian; dan c) pernyataan diri tentang kontribusi dosen yang bersangkutan dalam pelaksanaan dan pengembangan tridharma perguruan tinggi.

Dosen yang lulus penilaian portofolio mendapat sertifikat pendidik. Dosen yang tidak lulus penilaian portofolio melakukan kegiatan-kegiatan pengembangan profesionalisme guna memenuhi kelengkapan dokumen portofolionya untuk dinilai kembali dalam program sertifikasi periode berikutnya.

Untuk pengadaan tenaga pengajar Dosen, hanya bisa dilakukan oleh perguruan 
tinggi yang telah terakreditasi yang ditunjuk oleh pemerintah dan segala peraturan mengenai srtifikasi dosen dan penetapan perguruan tinggi terakreditasi penyelenggara program pengadaan tenaga pendidik diatur dalam Peraturan Pemerintah. Untuk memenuhi itu seorang dosen harus memiliki 4 (empat) kompetensi, yaitu:

1. Kompetensi Kepribadian

2. Kompetensi Profesional (Keilmuan dan Keterampilan)

3. Kompetensi Pedagogik

4. Kompetensi Sosial

\section{Model Kompetensi}

Model kompetensi didefinisikan sebagai suatu rangkaian kompetensi yang penting bagi kinerja yang superior dari sebuah pekerjaan atau sekelompok pekerjaan. Model kompetensi ini memberikan sebuah peta yang membantu seseorang memahami cara terbaik mencapai keberhasilan dalam pekerjaan ataumemahami cara mengatasi suatu situasi tertentu (LOMA, sCompetency Dictionary, 1998).

Menurut Kamus Kompetensi LOMA (1998) aplikasi dari model kompetensi pada sistem Manajemen Sumber Daya Manusia muncul pada area-area berikut:

1. Staffing. Strategi-strategirekrutmen dan tes-tes yang digunakan untuk seleksi didasarkan atas kompetensi-kompetesi kritikal dari pekerjaan

2. Evaluasi Kinerja. Penilaian kinerja dari pekerja didasarkan atas kompetensikompetensi pekerja diberikan kompensasi yang dikaitkan dengan target -target yang penting dari organisasi

3. Pelatihan. Program-program pelatihan dirancang untuk menjembatani kesenjangan antara kompetensi yang dimiliki pekerja dan kompetensi yang diharapkan dimiliki pekerja

4. Pengembangan. Para pekerja pertama kali diukur untuk mengenali kesenjangan kompetensinya; kemudian mereka dibimbing untuk membuat rencana-rencana pengambangan untuk menutupi kesenjangan yang ada.

5. Reward \& Recognition. Parapekerja diberikan kompensasi untuk prestasi-prestasi dan tingkah laku-tingkah laku yang mencerminkan tingkat ketrampilan mereka pada kompetensi-kompetensi kunci.

Hal tersebut di atas sejalan dengan pendapat dari Amstrong (2001) dalam Handbook ofHuman Resources Management Practice yang mengemukakanbahwa penerapan kompetensi dalam Manajemen SDM dilakukan dalam proses rekrutmen dan seleksi, assessment centres, manajemenkinerja, pengembangan SDM, dan manajemen imbal jasa.

\section{Teori Pasar Kerja}

Pasar kerja adalah seluruh aktivitas pelaku-pelaku ekonomi yang mempertemukan pencari kerja dan kesempatan kerja. Pelaku-pelaku tersebut terdiri dari: (1) pengusaha yang membutuhkan pekerja, dan (2) pencari kerja yang membutuhkan pekerjaan.

Proses interaksi keduanya membutuhkan waktu yang lama karena baik pencari kerja maupun kesempatan kerja tidak homogen dan informasi mengenai keduanya sangat terbatas. Pencari kerja ingin memperoleh pekerjaan dengan kondisi yang paling baik dan pengusaha ingin mencari pekerja yang paling cocok untuk mengisi lowongan.

Di dalam pasar kerja terjadi proses penempatan atau hubungan kerja melalui penyediaan dan permintaan tenaga kerja. Proses ini lebih lanjut dijelaskan dalam teori penawaran dan permintaan tenaga kerja. 


\section{Teori Kualitas Pelayanan}

Kualitas merupakan suatu kondisi dinamis yang berpengaruh dengan produk, jasa, manusia, proses dan lingkungan yang memenuhi atau melebihi harapan (Tjiptono, 2001). Sehingga definisi kualitas pelayanan dapat diartikan sebagai upaya pemenuhan kebutuhan dan keinginan konsumen serta ketepatan penyampaiannya dalam mengimbangi harapan konsumen (Tjiptono, 2007).

Kualitas pelayanan (servicequality) dapat diketahui dengancara membandingkan persepsi para konsumen atas pelayanan yang nyata-nyata mereka terima / peroleh dengan pelayanan yang sesungguhnya mereka harapkan / inginkan terhadap atribut-atribut pelayanan suatu perusahaan. Jika jasa yang diterima atau dirasakan (perceived service) sesuai dengan yang diharapkan, maka kualitas pelayananan dipersepsikan baik dan memuaskan, jika jasa yang diterima melampaui harapan konsumen, maka kualitas pelayanan dipersepsikan sangat baik dan berkualitas. Sebaliknya jika jasa yang diterima lebih rendah daripada yang diharapkan, maka kualitas pelayanan dipersepsikan buruk.

\subsection{Alumni}

Alumni adalah kata benda jamak dalam bahasa Inggris yang berarti lulusan pria dari suatu sekolah. Bentuk tunggalnya adalah alumnus. Sedangkan alumna juga kata benda jamak dalam bahasa Inggris yang berarti lulusan wanita dari suatu sekolah. Bentuk tunggalnya adalah alumnae (John M. Echols dan Hasan Shadily, 1995:25-26). Dalam studi penulusuran ini akan menggunakan istilah bahasa Inggris yang sudah diserap ke dalam bahasa Indonesia, yaitu alumni tanpa membedakan jenis kelamin dari lulusantersebut.

Penelusuran adalah kegiatan mencari informasi tentang hal yang belum diketahui dengan pasti. Informasi yang hendak digali dalam penelitian ini adalah tentang keberadaan alumni setelah meninggalkan bangku kuliah. Keberadaan alumni tersebut mencakup: (1) masa tunggu alumni semenjak lulus sampai dengan mendapatkan pekerjaan pertama, (2) tempat bekerja alumni, (3) perkembangan karir alumni, (4) cara alumni mengembangkan kemampuan akademik, (5) kepuasan stakeholders atas kinerja alumni, (6) kepuasan alumni atas kinerja program studi, (7) harapan stakeholders atas kinerja program studi, dan (8) harapan alumni atas kinerja program studi.

Kurikulum adalah seperangkat mata pelajaran yang diajarkan pada lembaga pendidikan atau seperangkat mata kuliah mengenai bidang keahlian khusus yang disajikan secara saling terkait satu sama lain (KBBI, 2002:617). Sampai saat ini belum ada kesatuan pendapat mengenai pengertian kurikulum. Pandangan lama menyatakan bahwa kurikulum merupakan seperangkat mata pelajaran dan materi pelajaran yang harus diajarkan oleh guru kepada peserta didik. (Moh. Ansyar dan Nurtain 1993).

Pengertian kurikulum dalam Undang-Undang No 20 Tahun 2003 tentang Sistem Pendidikan Nasional menyatakan bahwa kurikulum merupakan seperangkat dan pengaturan mengenai isi, tujuan dan bahan pelajaran serta cara yang digunakan sebagai pedoman penyelenggaraan kegiatan pembelajaran untuk mencapai tujuan pendidikan tertentu.

\section{Jenis Penelitian}

\section{METODE PENELITIAN}

Jenis penelitian yang digunakan dalam penelitian ini yaitu penelitian deskriptif. Penelitian deskriptif adalah penelitian yang dilakukan untuk mengetahui nilai variabel mandiri, baik satu variabel atau lebih (independent) tanpa membuat perbandingan, atau menghubungkan dengan variabel yang lain (Sugiyono, 2004:11). 


\section{Penentuan Subyek dan InformanPenelitian}

Subyek penelitian adalah semua dosen Jurusan Manajemen FEB dan alumni Jurusan Manajemen Fakultas Ekonomi dan Bisnis Universitas Mataram, tahun lulusan 2015-2016 periode yang tersebar di seluruh wilayah Nusantara.

\section{AnalisisData}

Teknik analisis data yang diperlukan dalam penelitian ini adalah sebagai berikut:

a. Reduksi data (DataReduction),

Proses ini dilaksanakan dengan memilah data dari catatan tertulis di lapangan,

b. Penyajian data (DisplayData),

Data yang telah direduksi, disajikan dalam laporan sistematis, mudah dibaca dan difahami, baik secara keseluruhan maupun per bagian,

c. Diskripsi data dengan bantuan statistic diskriptif

d. Pengambilan Kesimpulan (Verification)

Data yang telah diproses kemudian ditarik kesimpulan dengan menggunakan metode induktif, yaitu proses penyimpulan dari hal-hal yang sifatnya khusus ke hal-hal yang sifatnya umum agar diperoleh kesimpulan yang obyektif.

\section{HASIL DAN PEMBAHASAN}

\section{Kompetensi Dosen Manajemen Fak. Ekonomi dan Bisnis UnramSertifikasi Dosen}

Tuntuntan kompetensi yang bersifat langsung terkait dengan penguasaan dosen terhadap 4 (empat) kompetensi yang harus dimiliki dosen sesuai peraturan perundangundangan, yakni kompetensi pedagogik, kompetensi profesional, kompetensi sosial, dan kompetensi kepribadian. Sementara tuntutan kompetensi yang bersifat tidak langsung berupa kompetensi pendukung untuk melaksanakan tugas dosen sebagai pendidik dan ilmuwan, yakni kemampuan berbahasa Inggris dan potensi akademik yang dimiliki dosen.

Persentase Dosen yang Mendapat Tunjangan Sertifikasi, dari 60 orang dosen FEB jurusan manajemen sebanay 57 orang ( 95 persen) telah mendapat tunjangan serifikaasi dosen, sisanya belum mendapat sertifikasi dosen, ini berarti bahwa sebagian besar telah memenuhi syarat sebagai dosen yang berkompeten.

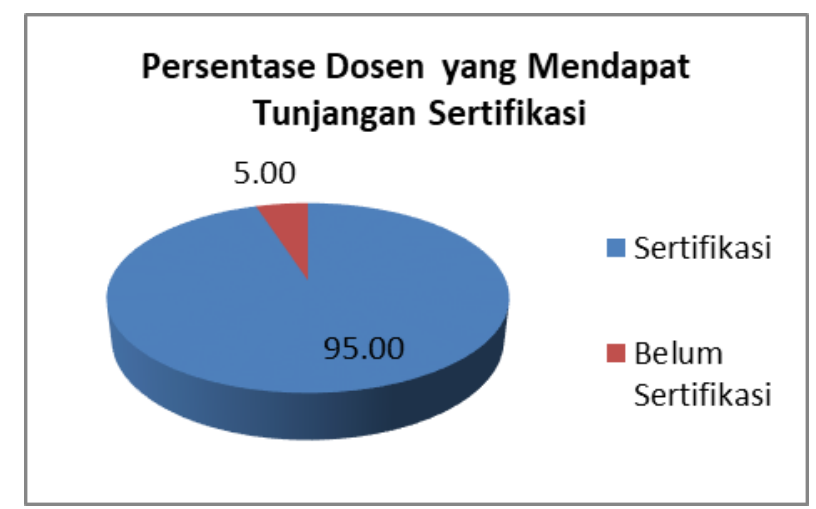

Tabel 1. Tabel Sertifikasi Dosen FEB Manajemen Unram

\begin{tabular}{|l|c|c|}
\hline Jabatan & Jumlah & Persentase \\
\hline Sertifikasi & 57 & 95.00 \\
\hline $\begin{array}{l}\text { Belum } \\
\text { Sertifikasi }\end{array}$ & 3 & 5.00 \\
\hline Jumlah & 60 & 100 \\
\hline
\end{tabular}

Kompetensi Perilaku Kerja

Untuk mengetahui kompetensi dosen dari sisi tindakan dan perilaku kerja dalam menyelesaikan suatu persoalan dapat dilihat dari sikapnya. 
Tabel 2. Skala Penilaian Perilaku Dosen FEB

Jurusan Manajemen Unram

\begin{tabular}{|c|c|}
\hline NILAI ANGKA & SEBUTAN \\
\hline $91-100$ & Sangat Baik \\
\hline $76-90$ & Baik \\
\hline $61-75$ & Cukup \\
\hline $51-60$ & Kurang \\
\hline 50 KE BAWAH & Buruk \\
\hline
\end{tabular}

Berdasarkan kriteria penilaian diatas Dari sisi perilaku kerja dosen FEB Manajemen Unram, Nilai maksismum, minimum dan rata-ratanya dapat dilihat pada tabel berikut:

Tabel 3. Hasil Rata-rata, Maksimum dan minimum Skala Penilaian Perilaku Dosen FEB Jurusan Manajemen Unram

\begin{tabular}{|l|c|c|c|}
\hline KETERANGAN & Maximum & Minimum & Rata-rata \\
\hline 1. Orientasi Pelayanan & 90 & 78 & 82.52 \\
\hline 2. Integritas & 91 & 78 & 82.7 \\
\hline 3. Komitmen & 93 & 86 & 90 \\
\hline 4. Disiplin & 90 & 78 & 82.91 \\
\hline 5. Kerjasama & 93 & 78 & 82.76 \\
\hline 6. Kepemimpinan & 89 & 77 & 81.61 \\
\hline Jumlah & & & \\
\hline
\end{tabular}

Sumber: data primer diolah

Dari kriteria penilaian diatas maka alokasi dosen dari sisi perilaku kerja dosen FEB Manajemen Unram, sebanyak 58 orang atau 95,08 persen berperilaku sangat baik, dan sisanya berperilaku baik, selengkapnya dapat dilihat pada tabel berikut:

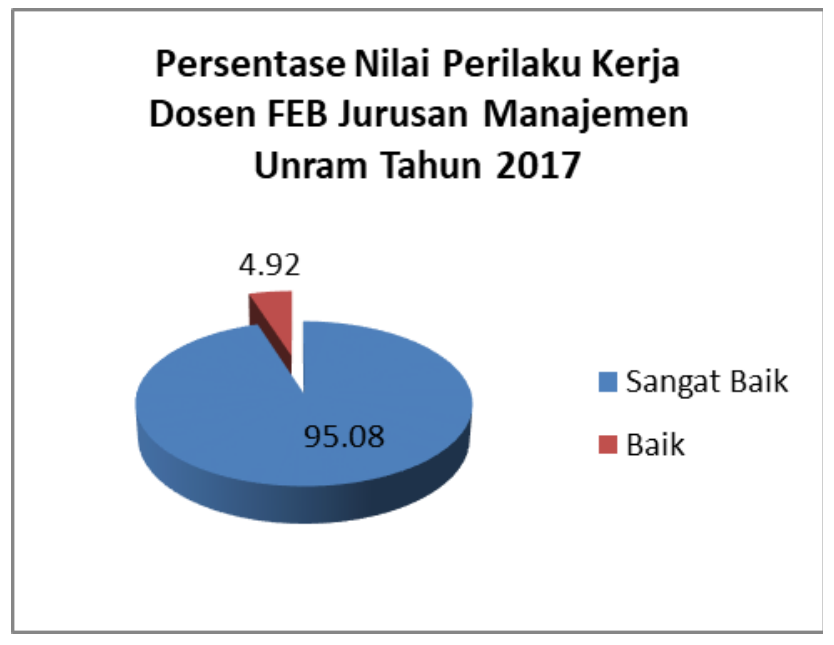

Sumber : data primer diolah

Tabel 4. Perilaku Kerja Dosen

Fakultas Ekonomi dan Bisnis Universitas Mataram

\begin{tabular}{|l|r|c|}
\hline $\begin{array}{c}\text { Nilai Perilaku } \\
\text { Kerja }\end{array}$ & $\begin{array}{c}\text { Jumla } \\
\mathrm{h} \\
\text { (orang } \\
\text { Sangat Baik }\end{array}$ & $\begin{array}{c}\text { Persentas } \\
\mathrm{e} \\
(\%)\end{array}$ \\
\hline Baik & 58 & 95.08 \\
\hline Cukup & 3 & 4.92 \\
\hline Kurang & - & - \\
\hline Buruk & - & - \\
\hline & - & - \\
\hline
\end{tabular}




\section{Kompetensi Pendidikan /Profesional}

Untuk mengetahui kompetensi dosen dari sisi tingkat pendidikan disamping pendidikan formal juga terhadap kemampuan dalam mengembangkan kemampuannya tersebut.

Tabel 5. Jabatan Fungsional Dosen Jurusan Manajemen FEB Unram

\begin{tabular}{|c|l|r|r|}
\hline No. & Jabatan & Jumlah & Persentase \\
\hline 1 & Guru Besar & 1 & 1.64 \\
\hline 2 & Lektor Kepala & 19 & 31.15 \\
\hline 3 & Lektor & 32 & 52.46 \\
\hline 4 & Asisten Ahli & 8 & 13.11 \\
\hline 5 & Prafungsional & 1 & 1.64 \\
\hline 6 & Jumlah & 61 & 100 \\
\hline
\end{tabular}

\section{Jabatan Fungsional Dosen} Jurusan Manajemen FEB Unram

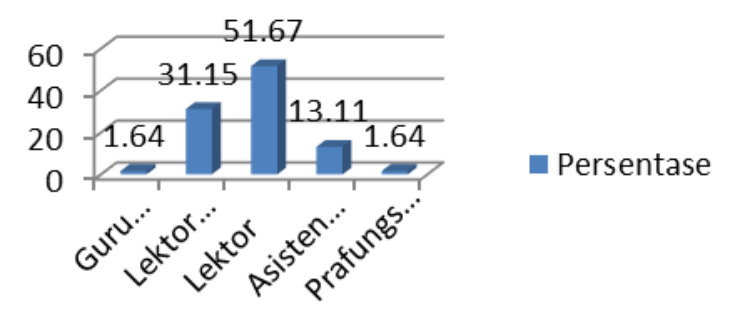

Sumber: data primer diolah

Jabatan Fungsional Dosen FEB Manajemen Unram, Jabatan Guru Besar 1 orang (1.64 persen), jabatan Lektor Kepala 19 orang (31.15 persen), jabatan Lektor 32 orang (52.46 persen), jabatan Asisten Ahli 8 orang (13.11 persen), dan jabatan Prafungsional 1 orang (1.64 persen)

Tabel 6. Tingkat Pendidikan Dosen Jurusan Manajemen FEB Unram

\begin{tabular}{|l|r|l}
\hline $\begin{array}{l}\text { Tingkat } \\
\text { Pendidikan }\end{array}$ & $\begin{array}{l}\text { Jumlah } \\
\text { (orang) }\end{array}$ & Persentase \\
\hline S-3 Doktor & 25 & 41.67 \\
\hline S-2 Magister & 35 & 58.33 \\
\hline Jumlah & 60 & 100.00 \\
\hline
\end{tabular}

Sumber: data primer diolah

\section{Tingkat Pendidikan} Dosen

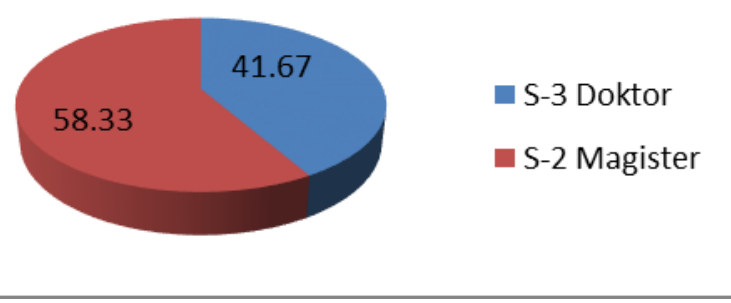

Tingkat Pendidikan Dosen FEB Sudah Menenuhi ketentuan yang sudah ada, dengan kondisi 41 persen (25 orang) sudah berpendidikan S-3, sisanya 58,33 persen (35 orang) berpendidikan S-2. Jabatan Guru Besar 1 orang (1.64 persen), jabatan Lektor Kepala 19 orang (31.15 persen), jabatan Lektor 32 orang (52.46 persen), jabatan Asisten Ahli 8 orang (13.11 persen), dan jabatan Prafungsional 1 orang (1.64 persen)

\section{Evaluasi Mahasiswa AtasKinerja DosenDalam Perkuliahan}

Dalam melaksamakam kegiata proses belajar mengajar, dosen dituntut mengusai metode dan tehnik mengajar, untuk menilai kemampuan dosen. Penilaian kinerja dosen dalam perkuliahan dilakukan dengan penyebaran kuesioner untuk mengetahui respon/pendapat mahasiswa selama perkuliahan yang dilakukan. Penilaian dilakukan terhadap 10 (sepuluh)unsur, seperti tampak dalam tabel berikut: 
Tabel 7. Unsur Penilaian Terhadap Kinerja Dosen Dalam Perkuliahan

\begin{tabular}{|c|l|}
\hline NO & \multicolumn{1}{c|}{ UNSUR PENILAIAN } \\
\hline 1 & $\begin{array}{l}\text { Untuk Mata Kuliah yang diampu, Tim Dosen yang masuk pada } \\
\text { pertemuan awal menyampaikan Rencana Perkuliahan } \\
\text { Semester (RPS)/Silabus/SAP) pada awal perkuliahan }\end{array}$ \\
\hline 2 & Ketaatan terhadap RPS/Silabus/SAP \\
\hline 3 & Ketepatan waktu mulai dan mengakhiri perkuliahan \\
\hline 4 & Frekuensi Kehadiran dosen \\
\hline 5 & Kemampuan dalam menjelaskan materi perkuliahan \\
\hline 6 & Pengkayaan dosen atas materi yang diberikan \\
\hline 7 & $\begin{array}{l}\text { Respon dosen terhadap pertanyaan/pernyataan mahasiswa } \\
\text { berkaitan dengan materi kuliah }\end{array}$ \\
\hline 8 & $\begin{array}{l}\text { Kemampuan dosen memotivasi dan menginspirasi mahasiswa } \\
\text { untuk belajar mandiri dan mengembangkan diri lebih lanjut } \\
\text { Dosen memberikan umpan balik terhadap hasil kerja } \\
\text { Mahasiswa }\end{array}$ \\
\hline 10 & $\begin{array}{l}\text { Pemanfaatan teknologi informasi dan komunikasi dalam } \\
\text { proses perkuliahan }\end{array}$ \\
\hline
\end{tabular}

Sepuluh unsur penilaian terhadap kinerja dosen dalam perkuliahan akan diukur dengan menggunakan skala penilaian $1-5$ dimana nilai $5=$ sangat baik; nilai 4 =baik, nilai $3=$ cukup, nilai $2=$ kurang, nilai $1=$ sangat kurang.

Hasil evaluasi kinerja dosen dalam perkuliahan pada semester Gasal TA.

2016/2017 ditampilkan dalam tabel berikut ini:

Berdasarkan Tabel 7 di atas, mahasiswa telah melakukan evaluasi terhadap kinerja dosen pada setiap mata kuliah yang diampu. Teknik penilaian ini dilakukan dengan menyebarkan kuesioner kepada beberapa mahasiswa yang dipilih secara acak. Kepada mereka sebelum mulai mengisi kuesioner, mahasiswa diberikan penjelasan mengenai tujuan pengisian kuesioner. Mahasiswa diberikan kebebasan penuh untuk menilai kinerja dosen tanpa adanya arahan untuk memberikan nilai-nilai tertentu. Hal ini dimaksudkan untuk menjaga kehandalan dalam memperoleh hasil penilaian. Kuesioner disebar pada waktu pertemuan terakhir dosen dengan mahasiswa dalam memberikan kuliah atau ketika ujian tengah semester dan akhir semester berlangsung.

Tabel 8. Hasil Penilaian Mahasiswa Terhadap Kinerja

\begin{tabular}{|l|c|c|}
\hline \multicolumn{1}{|c|}{ Kategori } & $\begin{array}{c}\text { Jumlah } \\
\text { Kelas }\end{array}$ & Persentase \\
\hline 1. Sangat kurang & - & - \\
\hline 2. Kurang & - & - \\
\hline 3. Cukup & 1 & 1 \\
\hline 4. Baik & 66 & 92 \\
\hline 5. Sangat baik & 5 & 7 \\
\hline Jumlah Kelas & 72 & 100 \\
\hline
\end{tabular}




\section{Dosen FEB Manajemen Dalam Perkuliahan}

Sumber data Primer diolah 2017

Hasil Penilaian Mahasiswa Terhadap Kinerja Mengajar Dosen di FEB Manajemen 2017, menyatakan bahwa sebanyak 92 persen menyatakan baik, sedangkan sisanya sebanyak 7 persen menyatakan sangat baik

Rekapitulasi hasil penilaian mahasiswa terhadap kinerja dosen menunjukkan hasil yang bervariasi mulai dari kategori cukup hingga sangat baik. Secara rata-rata hasil penilaian mahasiswa terhadap kinerja dosen tergolong baik dengan skor rata-rata sebesar 4. Hasil ini menunjukkan bahawa rata-rata dosen Jurusan manajemen telah memenuhi semua unsur penilaian dalam melaksanakan tugas mengajar sesuai dengan standar yang telah ditentukan.

Hasil penilaian mahasiswa di atas dapat dijadikan acuan bagi dosen untuk mempertahankan sekaligus meningkatkan cara dan teknik perkuliahan yang telah dilakukan. Terhadap item-item penilaian, dosen dapat melihat dan memperbaiki terhadap penilaian yang dirasakan belum memberikan kepuasan maksimal bagi mahasiswa.

Metode Pembelajaran oleh Dosen Berdasarkan Penilaian

Tabe19. Penilaian Mahasiswa Terhadap Dosen

\begin{tabular}{|l|c|r|r|r|r|}
\hline $\begin{array}{l}\text { Model } \\
\text { Pembelajaran }\end{array}$ & $\begin{array}{l}\text { Sangat } \\
\text { besar }\end{array}$ & Besar & $\begin{array}{l}\text { Cukup } \\
\text { Besar }\end{array}$ & Kurang & \multicolumn{2}{l|}{$\begin{array}{l}\text { Tidak sama } \\
\text { sekali }\end{array}$} \\
\hline Kuliah & 51.43 & 35.71 & 7.14 & 4.29 & 1.43 \\
\hline Demonstrasi & 4.29 & 17.14 & 20.00 & 28.57 & 30.00 \\
\hline Partisipasi riset & 1.43 & 18.57 & 11.43 & 17.14 & 51.43 \\
\hline Magang & 1.43 & 20.00 & 12.86 & 10.00 & 55.71 \\
\hline Praktikum & 4.29 & 21.43 & 42.86 & 28.57 & 2.86 \\
\hline PKL & 10.00 & 21.43 & 27.14 & 38.57 & 2.86 \\
\hline Diskusi & 35.71 & 51.43 & 11.43 & 1.43 & - \\
\hline
\end{tabular}

Sumber: Data Primer

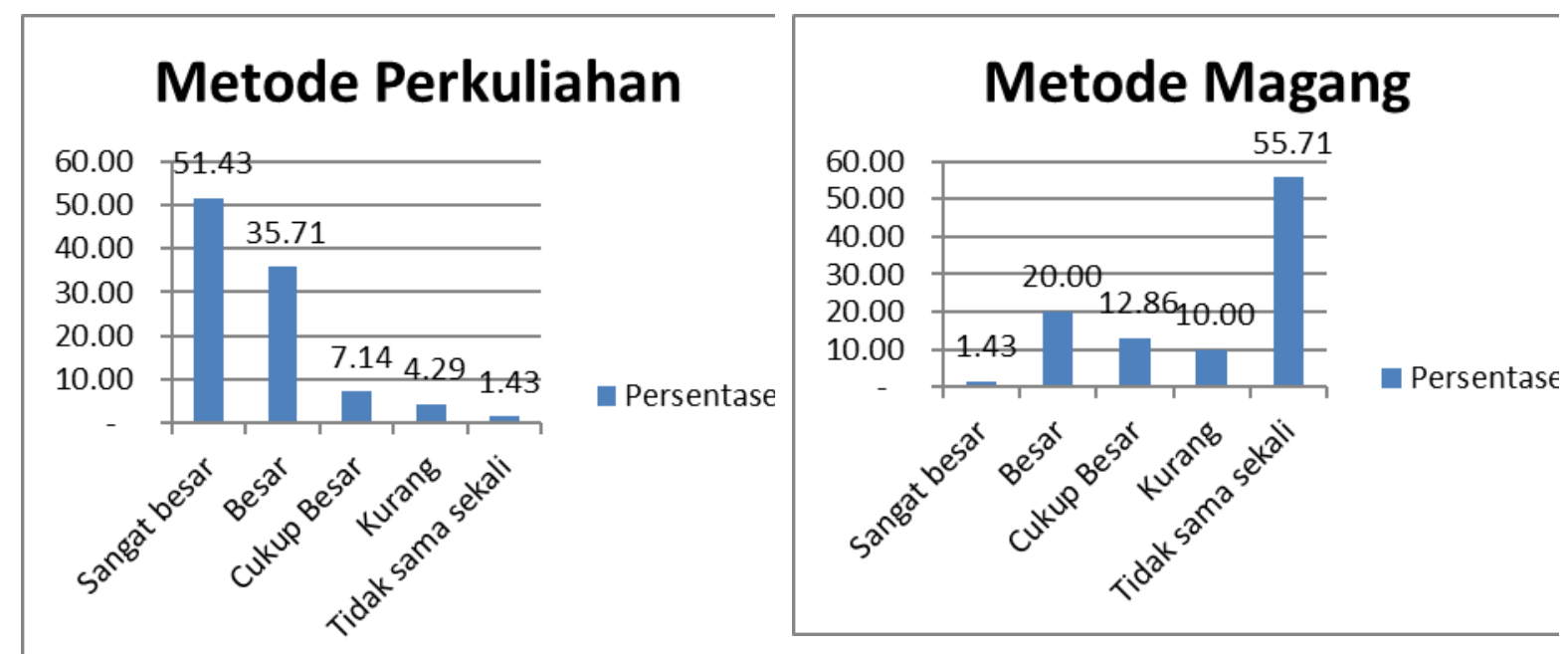

40 | Analisis Kompetensi Dosen Dan Alumni Fakultas Ekonomi Dan Bisnis... 

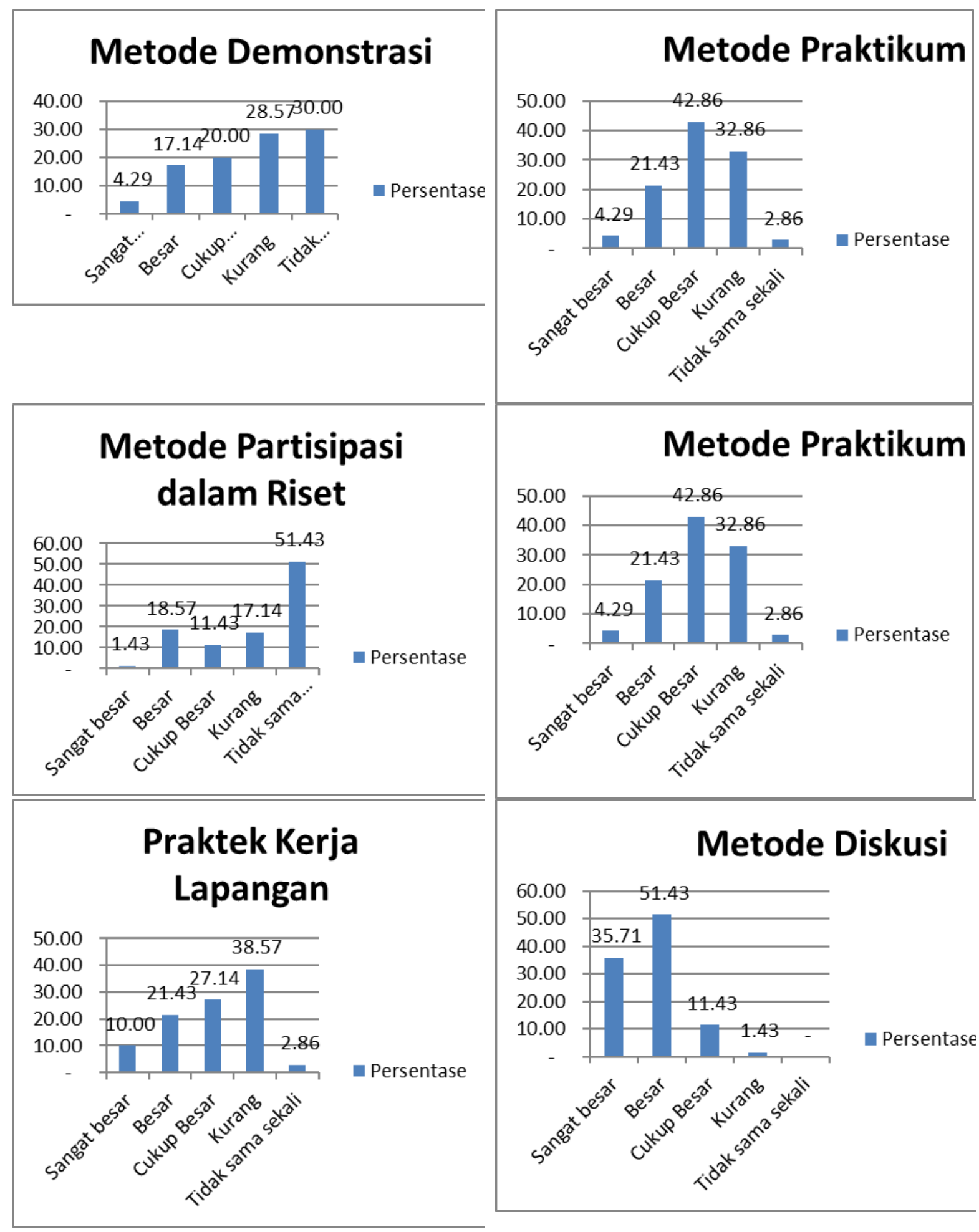

\section{Metode Diskusi}

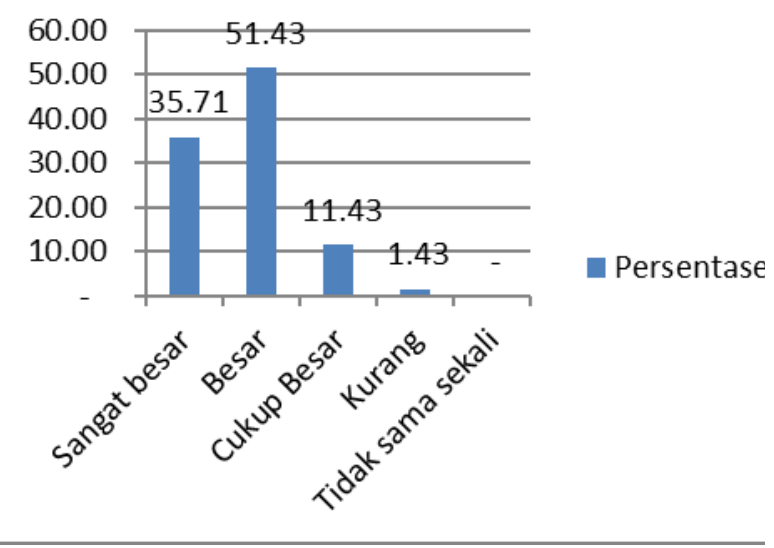




\section{Cara Alumni Mencari Pekerjaan}

\section{Cara Alumni Mencari Pekerjaan}

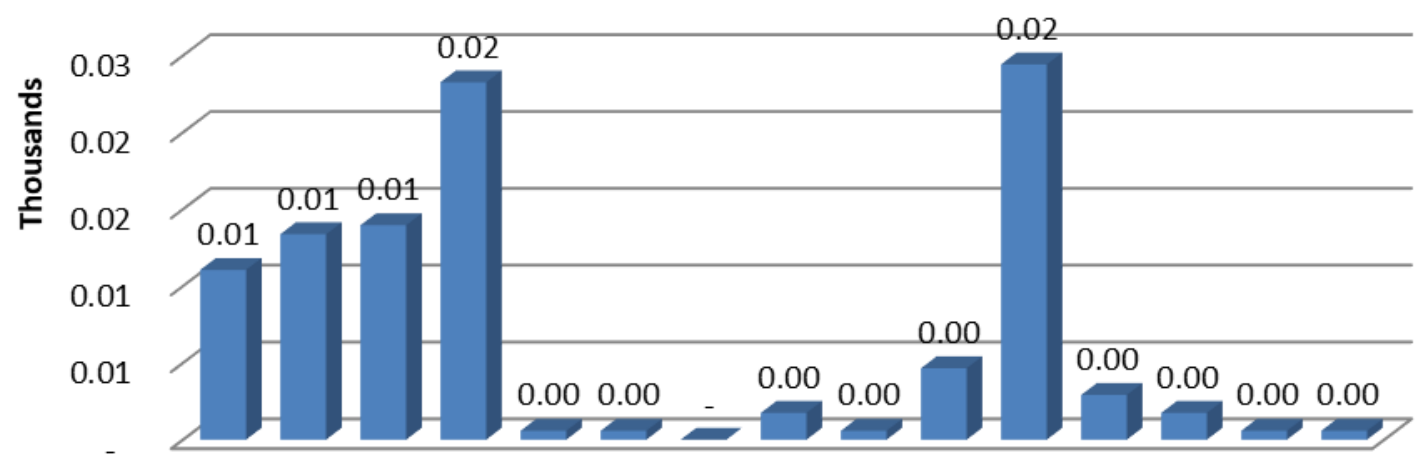

Periode Alumni Mendapatkan Pekerjaan

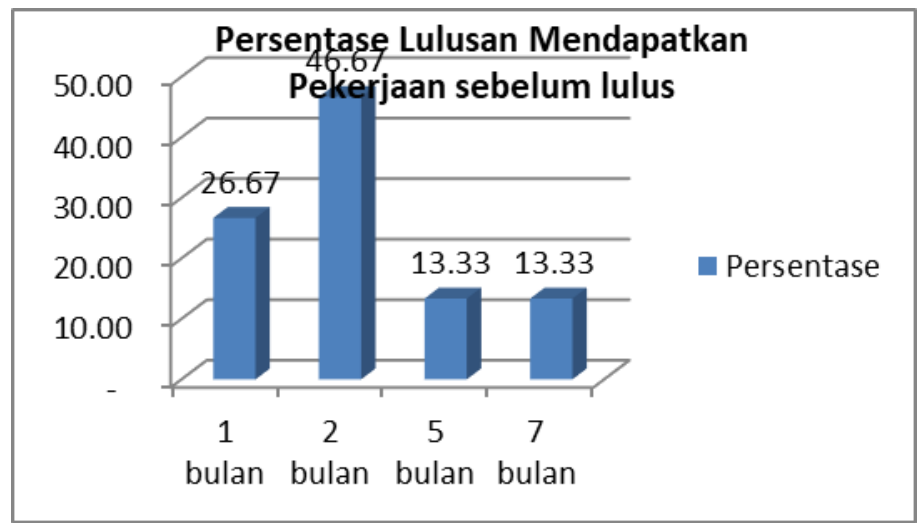

Mendapatkan Pekerjaan Sebelum lulus dari FEB

\begin{tabular}{|c|r|c|}
\hline $\begin{array}{c}\text { Sebelum } \\
\text { Lulus }\end{array}$ & $\begin{array}{r}\text { Jumlah } \\
\text { (orang) }\end{array}$ & Persentase \\
\hline 1 bulan & 4 & 26.67 \\
\hline 2 bulan & 7 & 46.67 \\
\hline 5 bulan & 2 & 13.33 \\
\hline 7 bulan & 2 & 13.33 \\
\hline Jumlah & 15 & 100.00 \\
\hline
\end{tabular}




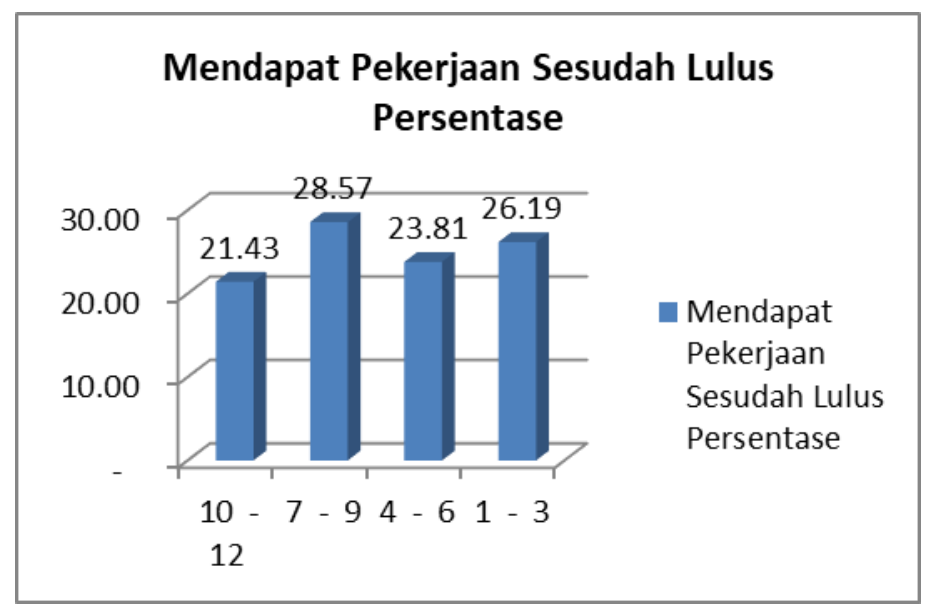

Mendapat Pekerjaan Sesudah Lulus

\begin{tabular}{|l|r|c|}
\hline $\begin{array}{c}\text { Setelah } \\
\text { Lulus }\end{array}$ & $\begin{array}{c}\text { Jumlah } \\
\text { (orang) }\end{array}$ & $\begin{array}{c}\text { Persentas } \\
\text { e }\end{array}$ \\
\hline $10-12$ & 9 & 21.43 \\
\hline $7-9$ & 12 & 28.57 \\
\hline $4-6$ & 10 & 23.81 \\
\hline $1-3$ & 11 & 26.19 \\
\hline Jumlah & 42 & 100.00 \\
\hline
\end{tabular}

\section{Kompetensi}

\section{KOMPETENSI YANG DIMILIKI ALUMNI PADA SAAT LULUS DAN KONTRIBUSI FEB TERHADAP KOMPETENSI TERSEBUT}

\begin{tabular}{|l|c|c|}
\hline \multicolumn{1}{|c|}{ Keterangan } & $\begin{array}{l}\text { Pada saat lulus, pada tingkat } \\
\text { mana kompetensi yang di } \\
\text { kuasai }\end{array}$ & $\begin{array}{c}\text { Pada saat lulus kontribusi } \\
\text { perguruan tinggi dalam hal } \\
\text { kompetensi di bawah ini }\end{array}$ \\
\hline Rata-rata & 3.39 & 3.58 \\
\hline Minimum & 2.80 & 2.23 \\
\hline Maksimum & 3.79 & 4.10 \\
\hline Standar Deviasi & 0.26 & 0.46 \\
\hline
\end{tabular}

Sumber Data Primer diolah

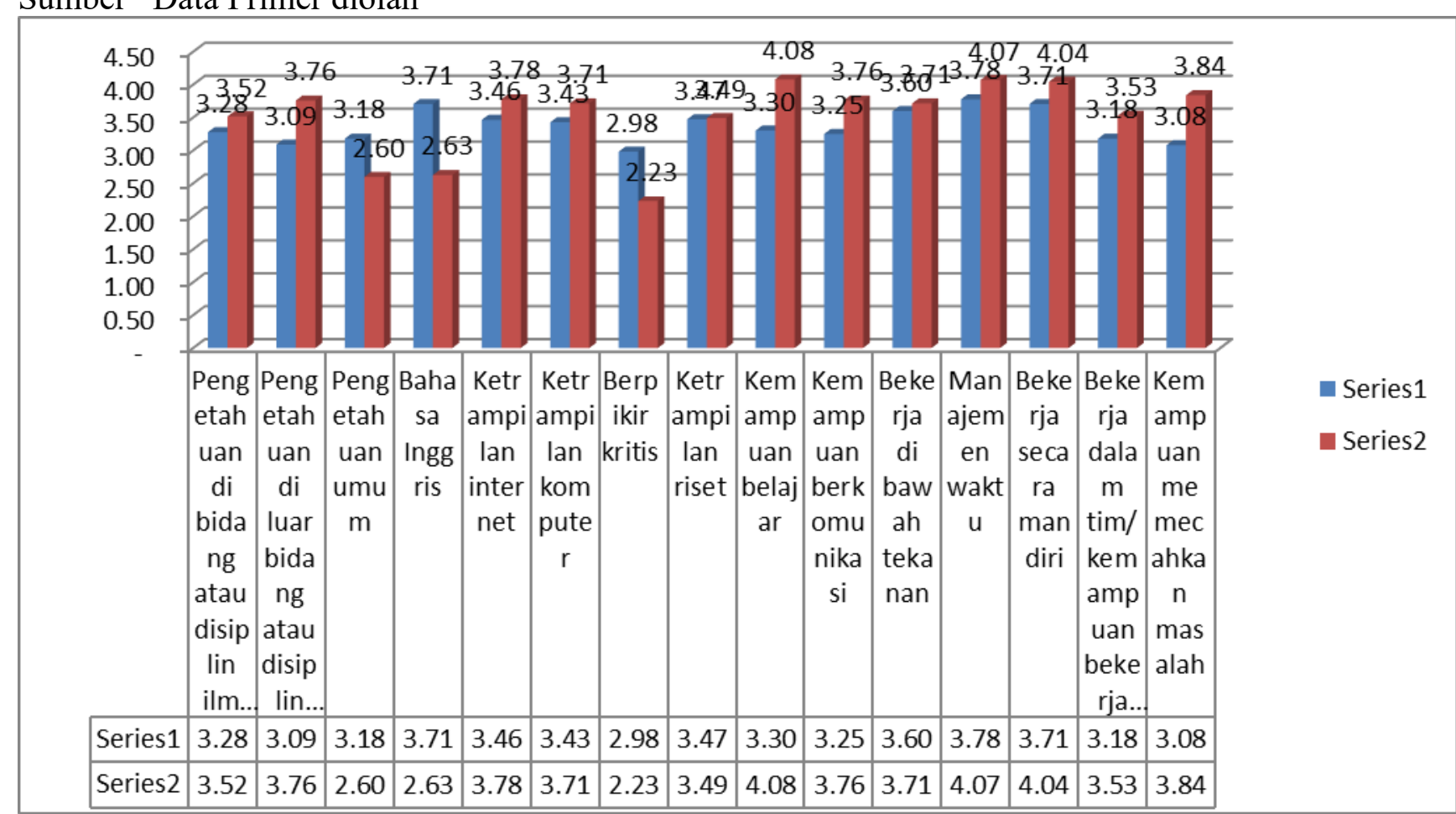




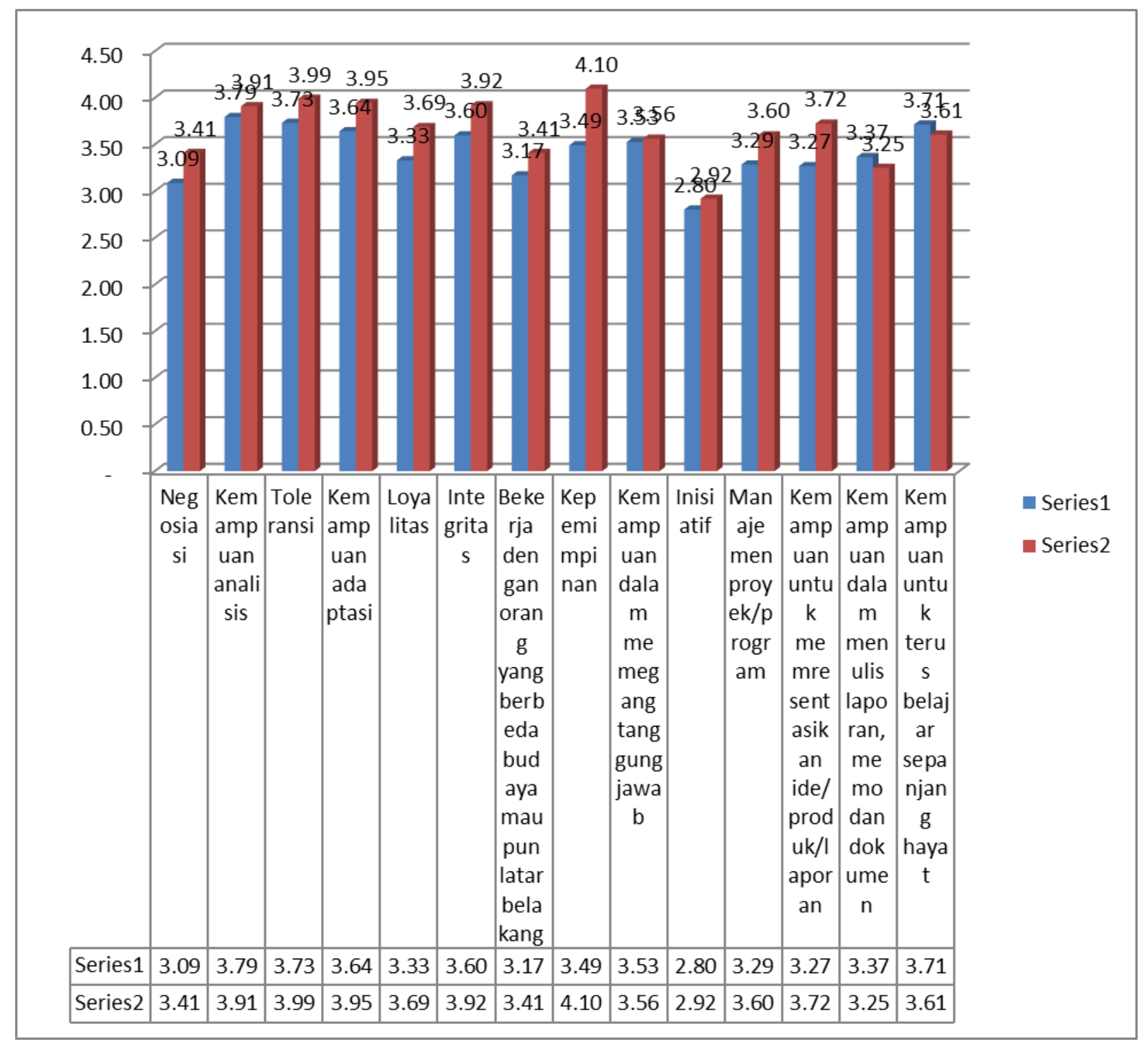

\section{Kesimpulan}

1) Kompetensi Dosen FEB Jurusan Manajemen ditinjau dari empat aspek

a. Persentase Dosen yang mendapat tunjangan sertifikasi, dari 60 orang dosen FEB jurusan manajemen sebanay 57 orang (95 persen) telah mendapat tunjangan serifikaasi dosen, sisanya belum mendapat sertifikasi dosen, ini berarti bahwa sebagian besar telah memenuhi syarat sebagai dosen yang berkompeten.

b. Dari sisi perilaku kerja dosen FEB Manajemen Unram, sebanyak 58 orang atau 95,08 persen berperilaku sangat baik, dan sisanya berperilaku baik

c. Jabatan Fungsional Dosen FEB Manajemen Unram, Jabatan Guru Besar 1 orang (1.64 persen), jabatan Lektor Kepala 19 orang (31.15 persen), jabatan Lektor 32 orang (52.46 persen), jabatan Asisten Ahli 8 orang (13.11 persen), dan jabatan Prafungsional 1 orang (1.64 persen)

d. Tingkat Pendidikan Dosen FEB sudah menenuhi ketentuan yang sudah ada, dengan kondisi 41 persen (25 orang) sudah berpendidikan S-3, sisanya 58,33 persen (35 orang) berpendidikan S-2.

2) Lama masa tunggu para alumni Manajemen FEB dalam memasuki dunia kerja, 14 orang mendapatkan pekerjaan sebelum lulus, 72,72 persen kurang dari 6 bulan, 15,15 
persen antara 7 sampai 9 bulan sedangkan sisanya diatas 10 bulan. Sebanyak 8,16 persen responden menyatakan bahwa antara latar belakang pendidikan dengan pekerjaan pertama yang ditekuni sangat erat, 32,65 persen menyatakan erat, 34,69 menyatakan cukup erat, 16,33 persen meyatakan kurang erat dan sisanya 8,16 persen menyatakan tidak sama sekali. Kompetensi Rata-rata alumni yang dikuasai selama mengikuti pendidikan di FEB Unram tinggi dengan nilai sebesar 3,21 dalam rentang 1 sampai 5. dan kontribusi dari FEB sebesar 3,48

\section{Saran}

Berdasarkan hasil penelitian dan kesimpulan maka dapat disarankan sebagaiberikut:

1. Agar tenaga dosen sebanyak 3 orang yang belum menedapat sertifikat pendidik segera diurus dan mendapat perhatian.

2. Agar diupayakan percepatan sebanyak 25 orang yang jenjang pendidikannya sudah $\mathrm{S} 3$ dan fungsional Lektor kepala menjadi guru besar dengan memfasilitasi untuk menulis artikel masuk ke jurnal internasional

3. Agar tenaga dosen sebanyak 45 orang masih jenjang Pendidikan S2 untuk bisa ditingkatkan pendidikannya ke jenjang S3 dengan memfasilitasi beasiswa baik untuk dalam negeri maupun luar negeri

4. Agar kurikulum pembelajaran selalu disesuaikan dengan kebutuhan lapangan kerja, dengan melibatkan stackholder. 


\section{DAFTAR PUSTAKA}

............ Badan Akreditasi Nasional Perguruan Tinggi,201, Akreditasi Institusi Perguruan Tinggi Buku III Pedoman Penyusunan Borang, Jakarta (ID); BAN-PT.

Badan Akreditasi Nasional Perguruan Tinggi,2011 Akreditasi Program Studi SarjanaBuku VI Matriks Penilaian Instrumen Akreditasi Program Studi Sarjana, Jakarta (ID); BAN-PT

A. Wahyuni Dkk, 2012, Analisis Relevansi Lulusan Perguruan Tinggi Dengan Dunia Kerja, Jurnal Economia, 8 (1).

Ansyar, Moh1989, Dasar-dasar Pengembanga Kurikulum, Depdiknas

Fuad Dkk, 2009, Integrated Human Rrsources development, Jakarta, PT. Grasindo

Masri Singrimbun, 1995, Metode Penelitian Survey, Jakarta, LP3ES Cetakan 2

Nasution, 1993, Pengembanga Kurikulum, Bandung, PT. Citra Aditya Bakti

Said Hamid Hasan, 1988, Evaluasi Kurikulum, P2LPTK, Dtjen Dikti, Depdibud Jakarta

Sudarwan Danim, 2002, Menjadi Peneliti Kualitatif, Bandung, Cetakan 1

Sugiyono, 2004, Metode Penelitian Bisnis, CV. Alfabeta, Bandung

Tjiptono, Fandy, 2001, Strategi Pemasaran, Edisi pertama, Andi Ofset, Yogyakarta 